Check for updates

Cite this: RSC Adv., 2018, 8, 31673

\title{
Design of nanostructured hybrid materials: twin polymerization of urethane-based twin prepolymers $\dagger$
}

\author{
D. Unlig, (D) a S. Spange, ${ }^{a}$ A. Seifert, ${ }^{a}$ K. Nagel, (D) ${ }^{a}$ S. Anders, ${ }^{b}$ L. Kroll, ${ }^{b}$ R. Stoll, ${ }^{c}$ \\ F. Thielbeer, ${ }^{d}$ P. Müller ${ }^{d}$ and K. Schreiter ${ }^{\star a}$
}

Organic-inorganic hybrid materials with urethane functionalities were obtained by simultaneous twin polymerization of twin prepolymers in combination with the ideal twin monomer 2,2'-spirobi[4H-1,3,2benzodioxasiline]. The twin prepolymers consist of a urethane-based prepolymer with reactive terminal groups which can react during the twin polymerization process. Nanostructured hybrid materials with integrated dialkylsiloxane crosslinked urethane structures, phenolic resin and $\mathrm{SiO}_{2}$ are obtained in a one pot process. The effects of the polymerization temperature as well as those of various catalysts and reagent ratios on the polymerization behavior were investigated. The molecular structures of the obtained materials were determined by ${ }^{13} \mathrm{C}$ - and ${ }^{29} \mathrm{Si}-\left\{{ }^{1} \mathrm{H}\right\}-\mathrm{CP}-\mathrm{MAS}$ NMR spectroscopies. HAADF-STEMmeasurements were performed to prove the distribution of silicon in the hybrid material.

Received 21st June 2018

Accepted 4th September 2018

DOI: $10.1039 / \mathrm{c} 8 \mathrm{ra0} 5310 \mathrm{c}$

rsc.li/rsc-advances

molecular level. ${ }^{\mathbf{1 0} 11}$ However, most established synthetic

\section{Introduction}

Nanostructured materials are one of the emerging areas of materials science and have attracted much attention because of their possible use in areas such as microelectronics, sensors, photovoltaics, electro-optical instruments, energy storage, conversion and separation processes as well as in catalysis..$^{1-9} \mathrm{In}$ recent years a variety of methods for the preparation of organicinorganic hybrid materials (HMs) have been developed which deliver defined nanostructures with domain sizes of 2 to $100 \mathrm{~nm}$. In particular silica-based organic-inorganic HMs have been investigated since they combine the distinctive properties of organic polymers (e.g. malleability, good impact resistance, flexibility) and silica (e.g. high mechanical strength, transparency, good chemical and thermal stability) as well as some special or new types of properties based on their specific microstructure. ${ }^{9}$

The sol-gel procedure and template-assisted polymerization are the most frequently used methods for preparing silica-based organic-inorganic HMs both on the micro scale and at the

${ }^{a}$ Department of Polymer Chemistry, Chemnitz University of Technology, Faculty of Natural Science, D-09107 Chemnitz, Germany. E-mail: katja.schreiter@chemie. tu-chemnitz.de

${ }^{b}$ Department of Lightweight Structures and Polymer Technology, Chemnitz University of Technology, Faculty of Mechanical Engineering, D-09107 Chemnitz, Germany ${ }^{\circ} B A S F$ Polyurethanes GmbH, Elastogranstraße 60, 49448 Lemfoerde, Germany ${ }^{d}$ BASF SE, Carl-Bosch Straße 38, 60756 Ludwigshafen, Germany

$\dagger$ Electronic supplementary information (ESI) available. See DOI: 10.1039/c8ra05310c methods require subsequent processing steps.

In recent years the twin polymerization (TP) turned out to be an elegant tool to prepare nanostructured HMs with domain sizes from 0.5 up to $10 \mathrm{~nm}$ whereby two different polymer phases result from only one single source monomer. ${ }^{12-16}$ For instance, the polymerization of the "ideal" twin monomer 2,2'spirobi-[4H-1,3,2-benzodioxasiline] (1) leads to a HM consisting of phenolic resin and silica (Scheme 1a)..$^{13,14}$ Different

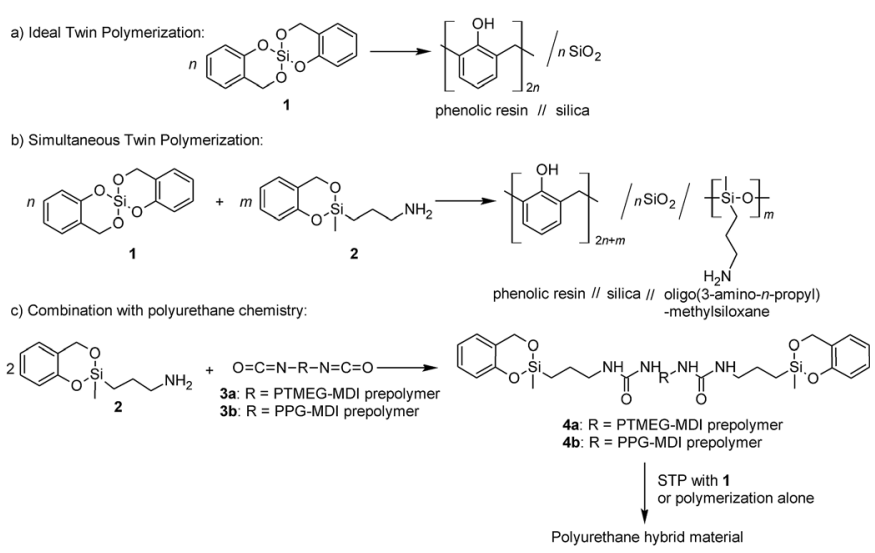

Scheme 1 (a) The "ideal" twin polymerization (TP) of 1 to generate a hybrid material consisting of phenolic resin and silica. (b) The introduction of (oligo)-dialkylsiloxane into phenolic resin/silica hybrid materials is possible by simultaneous TP (STP) of 1 with 2. (c) Endcapping of a polyurethane prepolymer with 2 and the subsequent STP results in hybrid materials consisting of phenolic resin, silica and diaIkylsiloxane-crosslinked PU. 


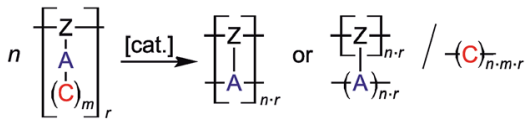

Scheme 2 Twin polymerization of a twin prepolymer. ${ }^{14}$

types of so-called twin monomers (TMs) are suitable for the TP. ${ }^{16-24}$ Depending on their molecular structure, two of these monomers can be polymerized simultaneously to generate ternary organic-inorganic HMs (see Scheme $1 b$ ). ${ }^{17,25,26}$

Polyurethanes (PUs) are outstanding materials due to their versatility and ability to generate tailor-made properties. The diversity had already been pointed out by $\mathrm{O}$. Bayer in the very first article about PUs. ${ }^{27}$ These materials fulfil the varied requirements of modern applications as form-memory polymers, adhesives, foams, fibers, thermoplastic elastomers and coatings. $^{28-30}$ As mentioned before, fabrication of nanocomposites or HMs consisting of silica species enables the improvement of material properties like tensile strength or flame retardancy. ${ }^{9,31}$ By combining the versatile world of PU chemistry with that of nanostructured HMs accessible by TP, such multicomponent HMs can become accessible. The objective of this work is to present a new concept for combining PU chemistry with that of organic-inorganic HM chemistry.

We describe here the first synthesis of nanostructured phenolic resin/urethane/ $/ \mathrm{SiO}_{2} \mathrm{HMs}$ by simultaneous twin polymerization (STP) using a novel type of urethane-based twin prepolymer and 1. A urethane-based twin prepolymer is a macromolecule or an oligomer molecule, which can be incorporated into the TP by means of its reactive groups. The synthesis of such twin prepolymers is a subtask of this work. They can be synthesized by use of an amino functionalized TM with isocyanate terminated prepolymer (Scheme 1c).

In the course of the (simultaneous) TP process various scenarios are possible for the formation of the molecular structure of the resulting polymer networks. The inorganic polymer $(\mathrm{A})_{n}$ can be obtained by reaction with reactive parts from the same or another polymer strand $[\mathrm{Z}]_{\mathrm{r}}$ or by a combination of both of these groups (Scheme 2).

Advantageously, the TP process of TM species with benzodioxasiline increments as reactive organic moiety can be induced thermally or by the use of acids or bases as catalyst. ${ }^{13,14,16,18}$ In this work, the polymerizations of the considered twin prepolymer systems will be thermally induced and triggered by the use of diazabicyclo[2.2.2] octane (DABCO), or diazabicyclo[5.4.0]undec7-ene (DBU) as base catalyst, respectively. The polymerization process is carried out in the melt, which is advantageous for possible applications as an adhesion promoter.

\section{Experimental}

\section{Materials and methods}

Diphenylmethane-4,4'-diisocyanate (MDI), polytetramethylene ether glycole (PTMEG, average molar weight $1000 \mathrm{~g} \mathrm{~mol}^{-1}$ ), polypropylene ether glycole (PPG, average molar weight $1000 \mathrm{~g}$ $\left.\mathrm{mol}^{-1}\right)$ and PTMEG-MDI-prepolymer (1500 $\left.\mathrm{g} \mathrm{mol}^{-1}\right)$ was provided by the BASF SE.
Salicylic alcohol (ABCR), 3-aminopropyl-dimethoxymethylsilane (TCI), tetra- $\mathrm{N}$-butylammonium fluoride (1 M solution; ABCR), diazabicyclo[2.2.2]octane (DABCO) (Sigma Aldrich), diazabicyclo [5.4.0]-undec-7-ene (DBU) (fluorochem) were used as received.

All solvents were dried with appropriate drying agents and freshly distilled before usage.

Liquid state ${ }^{1} \mathrm{H}$ NMR $(250.1 \mathrm{MHz}),{ }^{13} \mathrm{C}$ NMR $(62.9 \mathrm{MHz})$ and ${ }^{29} \mathrm{Si}$ NMR $(49.7 \mathrm{MHz})$ spectra were recorded with a Bruker DRX 250 NMR spectrometer. The residual signal of the solvent $\mathrm{CDCl}_{3}$ was used as an internal standard relative to tetramethylsilane (TMS; $\delta=0 \mathrm{ppm}$ ). The ${ }^{29} \mathrm{Si}$ NMR spectra are referenced to TMS $(\delta=0 \mathrm{ppm})$.

Solid state NMR spectra were collected at $9.4 \mathrm{~T}$ on a Bruker Avance 400 spectrometer equipped with double tuned probes capable of MAS (magic angle spinning). ${ }^{13} \mathrm{C}-\left\{{ }^{1} \mathrm{H}\right\}$-CP-MAS NMR spectra were measured at $100.6 \mathrm{MHz}$ in $3.2 \mathrm{~mm}$ standard zirconium oxide rotors (BRUKER) spinning at $15 \mathrm{kHz}$. Cross polarization with a contact time of $3 \mathrm{~ms}$ was used to enhance the sensitivity. The recycle delay was $6 \mathrm{~s}$. Spectra were referenced externally to tetramethylsilane (TMS) as well as to adamantane as secondary standard $\left(38.48 \mathrm{ppm}\right.$ for $\left.{ }^{13} \mathrm{C}\right) .{ }^{29} \mathrm{Si}-$ $\left\{{ }^{1} \mathrm{H}\right\}$-CP-MAS NMR spectroscopy was performed at $79.5 \mathrm{MHz}$ using $3.2 \mathrm{~mm}$ rotors spinning at $12 \mathrm{kHz}$. The contact time was $3 \mathrm{~ms}$ and the recycle delay $6 \mathrm{~s}$. Shifts were referenced externally to tetramethylsilane $(0 \mathrm{ppm})$ with the secondary standard being tetrakis(trimethylsilyl)silane $(-9.5 \mathrm{ppm})$. All spectra were collected with ${ }^{1} \mathrm{H}$ decoupling using a TPPM pulse sequence.

The high annular dark field (HAADF) scanning transmission electron microscopy (STEM) images were recorded with a Technai G2-F-20ST with HAADF-STEM-detector. The samples were prepared by ultramicrotomy.

Electron microscopy images were taken by using an instrument from type Nova NanoSEM 200 of FEI Company after sputtering with platinum.

The DSC measurements were performed by a DSC 1 (Mettler Toledo) and a DSC 204 F1 Phoenix (Netzsch) in a $40 \mu \mathrm{L}$ aluminum pan and a $\mathrm{N}_{2}$-flow of $50 \mathrm{~mL} \mathrm{~min}^{-1}$ in a temperature range of $30-300{ }^{\circ} \mathrm{C}$ or $30-350{ }^{\circ} \mathrm{C}$ with a heating rate of 10 $\mathrm{K} \mathrm{min}^{-1}$. The highest and the lowest temperature was held for 3 minutes, respectively.

TGA measurements were performed by a Thermogravimetric Analyzer 7. The samples were measured under air atmosphere, with a heating rate of $10 \mathrm{~K} \mathrm{~min}^{-1}$ from $30-900{ }^{\circ} \mathrm{C}$.

The TG/MS measurements were performed by a TG 209 F1 Iris (Netzsch) coupled to a Aëolos mass spectrometer (Bruker). The samples were prepared in a $85 \mu \mathrm{L}$ aluminum pan and measured under He-flow of $25 \mathrm{~mL} \mathrm{~min}{ }^{-1}$ in a temperature range of $25-350{ }^{\circ} \mathrm{C}$ with a heating rate of $10 \mathrm{~K} \mathrm{~min}^{-1}$. Before the start of the measurement, the sample room with sample was subjected twice to an evacuation and rinsing cycle with helium.

Size exclusion chromatography (SEC) was performed with a PL-GPC 50 plus from Polymer Laboratories equipped with a PL-AS RT auto sampler and a PC-RI detector. THF was used as eluent with a flow rate of $1.0 \mathrm{~mL} \min ^{-1}$ at $40{ }^{\circ} \mathrm{C}$. The column was a PLgel MIXED-D. 


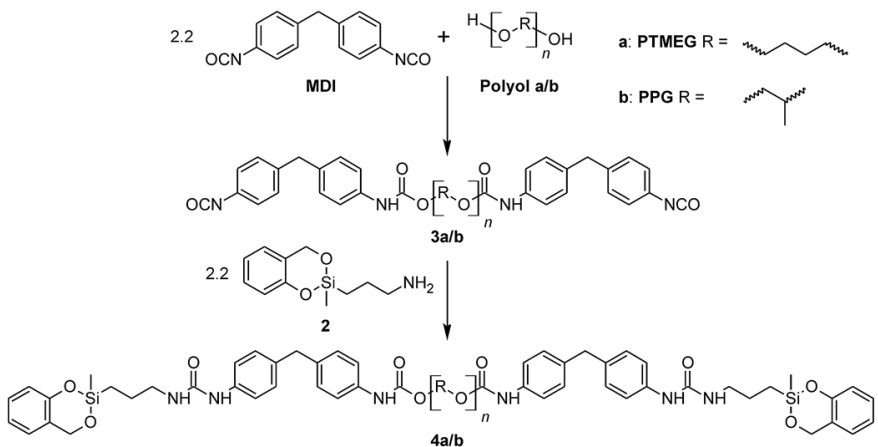

Scheme 3 General procedure for preparation of the twin prepolymer $4 \mathrm{a}$ and $4 \mathrm{~b}$.

The ATR-FTIR-spectra were recorded with a FTS 165 spectrometer (BioRad). A Golden Gate-single reflection-ATR-stage (L.O.T. Oriel $\mathrm{GmbH}$ ) was used. The samples were pressed against the detection system with a sapphire stamp (5 bar).

Elemental analysis was determined with a Vario El analyser (Elementar analysensysteme $\mathrm{GmbH}$ ).

\section{Synthetic procedures}

Synthesis of the monomers. The synthesis of $2,2^{\prime}$ spirobi- $\left[4 H^{-}\right.$ 1,3,2-benzodioxasiline] (1) and 2-(3-aminopropyl)-2-methyl-4H1,3,2-benzodioxasiline (2) was already described in the literature and performed accordingly. ${ }^{12,17}$

Procedure for the preparation of $3 a / b$ (spectral data can be found in the $\mathbf{E S I} \dagger$ ). 2.2 equivalents MDI were heated to $50{ }^{\circ} \mathrm{C}$. One equivalent PTMEG (for 3a) or PPG (for $\mathbf{3 b}$ ) was added under stirring to the molten diisocyanate by a dropping funnel within 15 minutes. Afterwards, the reaction mixture was heated to $98{ }^{\circ} \mathrm{C}$ for $2 \mathrm{~h}$.

General procedure for end-capping of prepolymer in substance. The end-capping was performed subsequently to the prepolymer preparation. Under stirring, 2.2 equivalents 2 were slowly added with a syringe through a septum to the prepolymer $3 \mathbf{a}$ or $3 \mathbf{b}$ at $70{ }^{\circ} \mathrm{C}$. During the addition of 2 the temperature was kept below $100{ }^{\circ} \mathrm{C}$. The reaction mixture was stirred at $70{ }^{\circ} \mathrm{C}$ for 30 minutes to give the products $\mathbf{4 a}$ or $\mathbf{4 b}$.

\section{Polymerization}

General procedure for the thermal induced STP of $4 a / b$ with 1. The respective amounts of $\mathbf{4 a} / \mathbf{b}$ and $\mathbf{1}$ were placed in a PTFEwide-neck-flask with screw-cap and magnetic stirrer under argon. Under stirring, the flask was heated to $125^{\circ} \mathrm{C}$ for $0.5 \mathrm{~h}$ to give a homogeneous melt. The magnetic stirrer was removed from the slightly yellow reaction mixture. Afterwards the reaction-flask was heated to the respective polymerization temperature for $2 \mathrm{~h}$.

Detailed information are summarized in the ESI. The monomer amounts, extractable contents as well as the found silicon contents are listed in Tables $2 / 3$.

\section{Extraction}

The obtained materials were cut into small pieces with a scalpel. About $1 \mathrm{~g}$ of the material pieces were placed in an extraction thimble and Soxhlet-extracted with $200 \mathrm{~mL}$ dichloromethane for $48 \mathrm{~h}$. The extracted material was dried in a vacuum oven at $40{ }^{\circ} \mathrm{C}$ until weight constant. The solvent was removed under reduced pressure to give the concentrated extract.

\section{Results and discussion}

The reactive prepolymers $\mathbf{4 a}$ and $\mathbf{4 b}$ were obtained by endcapping of the PU prepolymers $\mathbf{3 a}$ or $\mathbf{3 b}$ with 2-(3-aminopropyl)-2-methyl-4H-1,3,2-benzodioxasiline (2), respectively.

In accordance to the classification of TM species and polymerization processes, a so-called twin prepolymer was generated (Scheme 3). ${ }^{\mathbf{1 4}}$

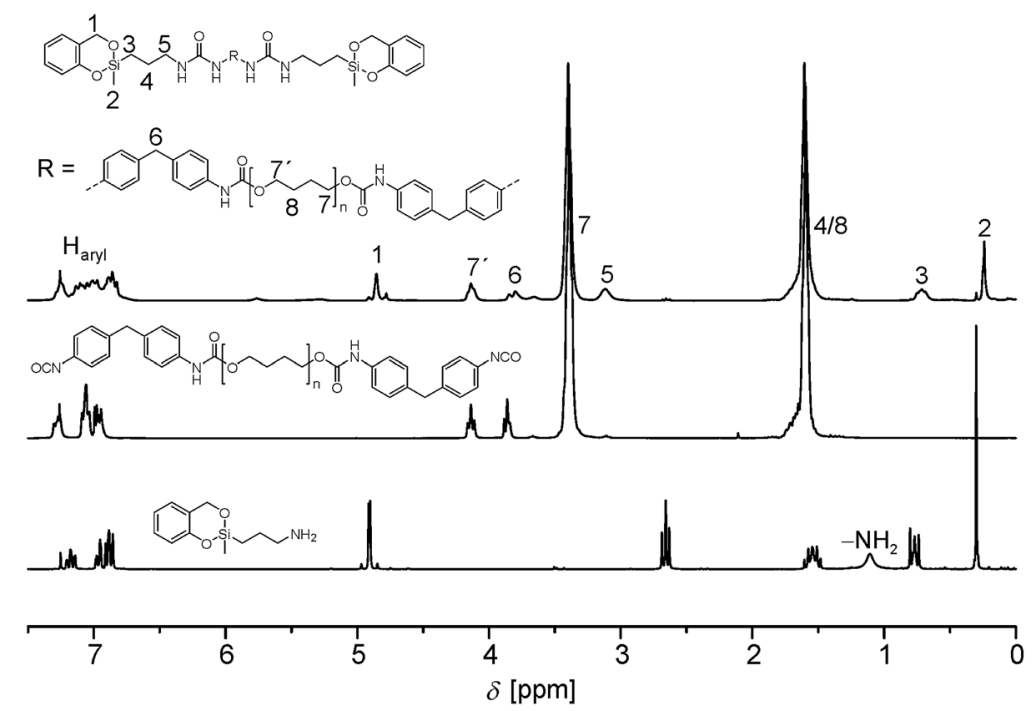

Fig. $1{ }^{1} \mathrm{H}$ NMR spectrum of $4 \mathrm{a}$ (top) in combination with the spectra of the corresponding educts 2 (bottom) and 3 a (middle, all spectra measured in $\mathrm{CDCl}_{3}$ ). 
A representative ${ }^{1} \mathrm{H}$ NMR spectrum of $4 a$ is shown in Fig. 1. The disappearance of the $\mathrm{NH}_{2}$ signal and the down field shift of the neighboring $\mathrm{CH}_{2}$ group of 2 (signal 5) prove the successful reaction of the amino functionality with isocyanate.

Due to the required excess of diisocyanate used during the preparation of the prepolymer, low molecular by-products can be detected by GPC measurement (Fig. S4/S5 and Tables S1/ $\mathrm{S} 2 \dagger)$. Those by-products have to be taken into account for the subsequent polymerization and its interpretation.

\section{Thermal initiation - preliminary investigation}

Polymerization ability of the twin prepolymers $\mathbf{4 a}$ and $\mathbf{4 b}$ were studied using differential scanning calorimetry (DSC). Various reaction scenarios are apparent from the temperature profiles, showing the reaction of a twin prepolymer alone, in the presence of a second TM or with a potential catalyst (Fig. 2). Homogenous monomer mixtures were prepared by melting all components at $100{ }^{\circ} \mathrm{C}$ prior to the DSC measurements.

Upon heating the twin prepolymer $4 \mathbf{a}$, an exothermic peak at $279{ }^{\circ} \mathrm{C}\left(T_{\text {onset }}=234{ }^{\circ} \mathrm{C}\right.$, Fig. 2 bottom $)$ is observed. The addition of 1 reduces the trigger temperature as indicated by the exothermic peak to $245{ }^{\circ} \mathrm{C}\left(T_{\text {onset }}=150{ }^{\circ} \mathrm{C}\right.$, Fig. 2 middle $)$. If $\mathrm{DABCO}$ is added as a catalyst to that mixture a further reduction of the polymerization trigger temperature (Fig. 2 top) is measured. Two exothermic peaks $\left(T_{\text {onset1 }}=117{ }^{\circ} \mathrm{C}, T_{\text {peak1 }}=\right.$ $142{ }^{\circ} \mathrm{C} ; T_{\text {onset } 2}=195{ }^{\circ} \mathrm{C}, T_{\text {peak } 2}=229{ }^{\circ} \mathrm{C}$ ) are obtained, the first one indicating its catalytic activity.

The addition of lactic acid as catalyst to the mixture of $\mathbf{4 a}$ and $\mathbf{1}$ already leads to polymerization at a temperature of approx. $80^{\circ} \mathrm{C}$. However, a prerequisite for a polymerization in the melt of $4 \mathrm{a}$ and $\mathbf{1}$ is a mixing of the components at approx. $100{ }^{\circ} \mathrm{C}$. Otherwise, inhomogeneous products are created due to the high viscosity of the reaction mixture. Therefore, acid catalysis was not preferred in this work, although this problem can be solved by using a solvent but that is not useful for the objective of this work.

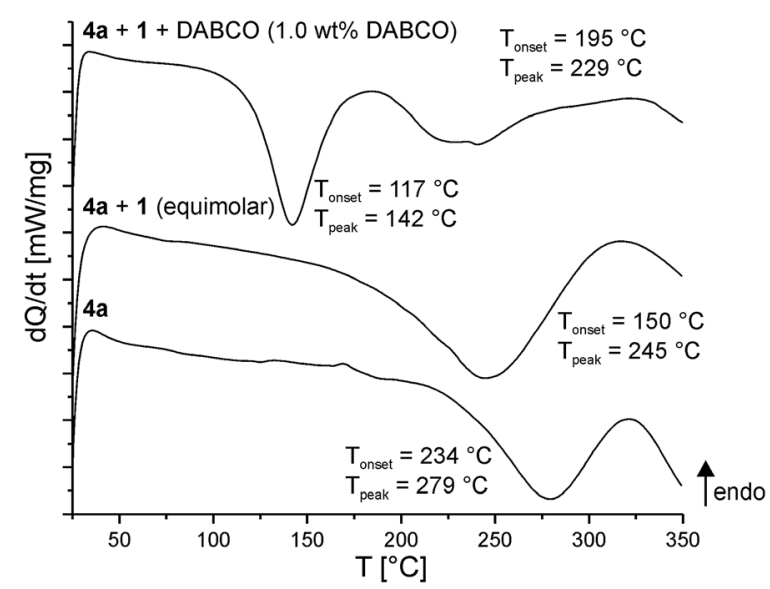

Fig. 2 DSC curves of the twin prepolymer 4 a alone, with equimolar amounts of 1 and an equimolar mixture of $4 \mathrm{a}$ and 1 with $1.0 \mathrm{wt} \%$ of base catalyst (DABCO); heating rate $10 \mathrm{~K} \mathrm{~min}^{-1}$.
Table 1 Characteristic trigger temperatures for thermally induced and DABCO catalyzed STP of different monomer mixtures of $4 \mathrm{a}$ or $4 \mathrm{~b}$ with 1 as determined by DSC measurements

\begin{tabular}{lll}
\hline & \multicolumn{2}{l}{$T_{\text {onset,exo }}\left(T_{\text {peak,exo }}\right)\left[{ }^{\circ} \mathrm{C}\right]$} \\
\cline { 2 - 3 } & $\mathbf{4 a}$ & $\mathbf{4 b}$ \\
\hline Pure & $234(279)$ & $245(293)$ \\
$+\mathbf{1}+$ DABCO & $150(245)$ & $191(237)$ \\
& $117(142)$ & $134(148)$ \\
& $195(229)$ &
\end{tabular}

4b alone shows an exothermic peak at $293{ }^{\circ} \mathrm{C}$. The addition of 1 and DABCO results in similar trends to lower temperatures as observed for $\mathbf{4 a}$ (Table 1 and Fig. S12†).

These preliminary results were confirmed by reproducing these polymerizations on a multi-gram scale and subsequent analysis of the products. Monolithic HMs were prepared by thermal polymerization, with the addition of either DABCO or DBU as catalysts.

\section{Thermally induced (simultaneous) twin polymerization}

The prepolymers $\mathbf{4 a}$ or $\mathbf{4 b}$ were polymerized simultaneously with 1 at $170{ }^{\circ} \mathrm{C}, 190{ }^{\circ} \mathrm{C}, 210^{\circ} \mathrm{C}$ as well as $230{ }^{\circ} \mathrm{C}$ for $2 \mathrm{~h}$ using a stoichiometric ratio of $1: 1$ (Table 2). The yellow colored materials obtained are readily foamed and elastic. According to the concept of STP, the resulting organic-inorganic HM should consist of phenolic resin, $\mathrm{SiO}_{2}$ and oligodialkylsiloxane (ODAS) with integrated urethane structural units which also have a cross-linking function. The $\mathrm{SiO}_{2}$ and ODAS groups can form $\mathrm{Si}-\mathrm{O}-\mathrm{Si}$ bonds and thus form a class II hybrid structure among the phenolic resin/ $/ \mathrm{SiO}_{2} / \mathrm{ODAS}$ hybrid compounds according to the classification of Sanchez ${ }^{32}$ (Scheme 4). This is verified by ${ }^{29} \mathrm{Si}$ and ${ }^{13} \mathrm{C}$ solid state NMR spectroscopy of the HMs (Fig. S6†).

Each of the ${ }^{29} \mathrm{Si}-\left\{{ }^{1} \mathrm{H}\right\}$-CP-MAS NMR spectrum of HMs show the expected $\mathrm{Q}$ and $\mathrm{D}$ signals resulting from monomer $\mathbf{1}$ and the corresponding twin prepolymer, respectively. The $\mathrm{Q}_{4}$ signals measured at $-110 \mathrm{ppm}$ are the most intense signals in the silica range $(=\mathrm{Q})$ of the ${ }^{29} \mathrm{Si}$ NMR spectrum in each case. The cross polarization technique used to enhance the sensitivity

Table 2 Summary of the synthesis conditions of the hybrid materials and the composition as measured by thermogravimetric analysis (TGA) after extraction. Reaction time $t=2 \mathrm{~h}$. Calculated silica content $=$ $8.1 \mathrm{wt} \%$

\begin{tabular}{lllll}
\hline Sample & $\begin{array}{l}\text { Molar ratio } \\
{[\mathrm{mol} \%]}\end{array} n_{\mathbf{4 a} / \mathbf{b}}: n_{\mathbf{1}}$ & Temp. $\left[{ }^{\circ} \mathrm{C}\right]$ & $\begin{array}{l}\text { Extr. cont. } \\
{[\mathrm{wt} \%]}\end{array}$ & $\begin{array}{l}\text { Silica cont. } \\
{[\mathrm{wt} \%]}\end{array}$ \\
\hline HM5a_170 & \multirow{2}{*}{$50: 50$} & 170 & 47 & 10.7 \\
HM5a_190 & & 190 & 47 & 11.1 \\
HM5a_210 & & 210 & 35 & 9.2 \\
HM5a_230 & & 230 & 36 & 10.5 \\
HM5b_170 & \multirow{2}{*}{$50: 50$} & 170 & 84 & - \\
HM5b_190 & & 190 & 49 & 11.1 \\
HM5b_210 & & 210 & 33 & 11.5 \\
HM5b_230 & & 230 & 45 & 9.2
\end{tabular}




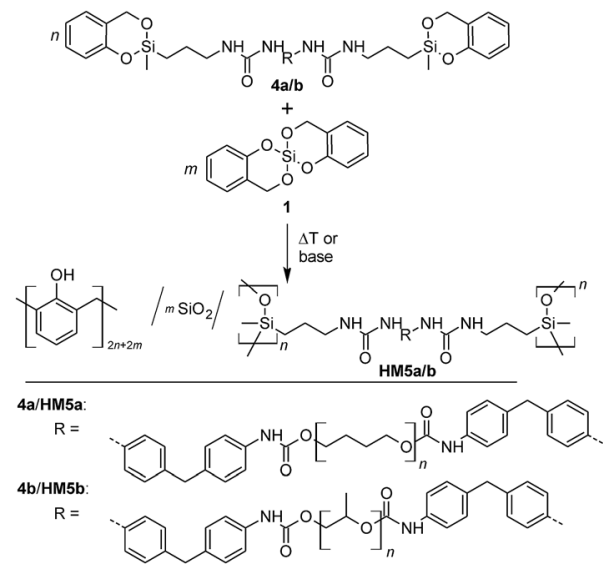

Scheme 4 Reaction scheme for the STP of $4 a / b$ with 1.

overestimates $\mathrm{Q}_{2}(-90 \mathrm{ppm})$ and $\mathrm{Q}_{3}(-100 \mathrm{ppm})$ over $\mathrm{Q}_{4}$ because these are silicon species with hydrogen in close proximity resulting in a more efficient polarization transfer from ${ }^{1} \mathrm{H}$ to ${ }^{29} \mathrm{Si}$. The high intensity of the $\mathrm{Q}_{4}$ signals in comparison to $\mathrm{Q}_{2}$ and $\mathrm{Q}_{3}$ found in the products clearly shows that the $\mathrm{SiO}_{2}$ network must nearly be fully condensed.

The $\mathrm{D}_{1}, \mathrm{D}(\mathrm{Q})$ and $\mathrm{D}_{2}$ signals observed in the range from -10 to $-23 \mathrm{ppm}$ correspond to bifunctional (D) silicon structures originating from $4 \mathbf{a}$, or $\mathbf{4 b}$. $\mathrm{D}(\mathrm{Q})$ signals are also found at about -16 to $-17 \mathrm{ppm}$. These are characteristic for the STP products indicating a reduced flexibility of the oligodialkylsiloxane (ODAS) part and thus the binding of ODAS to the $\mathrm{SiO}_{2}$ network. According to the classification of STP processes, ${ }^{25}$ this is therefore a real simultaneous twin copolymerization. The observation of a $\mathrm{D}_{1}$ (one siloxane bond, $\mathrm{Si}-\mathrm{O}-\mathrm{Si}-$ ) signal at $\approx-7 \mathrm{ppm}$ probably corresponds to end groups of ODAS. No signals from the monomer reactants were detected in the solid state ${ }^{29} \mathrm{Si}$ NMR spectra.

The formation of phenolic resin, ODAS and urethane structures can be proven by ${ }^{13} \mathrm{C}-\left\{{ }^{1} \mathrm{H}\right\}$-CP-MAS NMR spectroscopy. The $o, o^{\prime}$ - and $o, p^{\prime}$-bonded phenolic resin structures can be detected by the signals in the aromatic region (signals 3 and 5, Fig. S6†). The signal for the bridging methylene group (signal 4) is overlaid with the intense signal of the $\mathrm{CH}_{2}$ groups of the ether fragment (signal 15). The ODAS structure gives a signal for the methyl group at $0 \mathrm{ppm}$. The signals for the carbon atoms of the alkyl chains of ODAS are observed in the expected region of 18-70 ppm, whereby the most intense carbon signals at 26 and $70 \mathrm{ppm}$ are due to the methylene groups of the ether fragments (signals 14 and 15). Furthermore, the presence of signals at $42 \mathrm{ppm}$ (signal 11), between 110-140 ppm (signal 12) and $155 \mathrm{ppm}$ (signal 10 and 13), shows that the urethane fragment is bonded to $\mathrm{HM}$ after the polymerization and subsequent extraction.

Soxhlet-extraction of the raw HM with dichloromethane (DCM) gave extractable fractions, which were identified as prepolymer and low molecular weight products such as salicylic alcohol (Fig. S7 and Table S7†). Depending on the polymer backbone chosen, the quantity of the extractable fraction was very different. Using $\mathbf{4 a}$ gives an extractable portion of $47 \mathrm{wt} \%$ whereas with $\mathbf{4 b}$ the extractable portion increases to $84 \mathrm{wt} \%$. These extraction experiments together with the results of the DSC (Fig. S12 $\dagger$ ) show that for the system $\mathbf{4 b}: \mathbf{1}$ a polymerization temperature of $170{ }^{\circ} \mathrm{C}$ is too low (Table 2).

Thus, the HMs of the monomers $\mathbf{1}$ and $\mathbf{4 a}$ or $\mathbf{4 b}$ were polymerized at higher temperatures $\left(190{ }^{\circ} \mathrm{C} / 210{ }^{\circ} \mathrm{C} / 230{ }^{\circ} \mathrm{C}\right)$ to increase the conversion.

Increasing the polymerization temperature to $210{ }^{\circ} \mathrm{C}$ results in a reduction of the extractable proportions of the resulting HMs to $\approx 35 \mathrm{wt} \%$ for $4 \mathbf{a}$ and $\approx 33 \mathrm{wt} \%$ for $4 \mathbf{b}\left(T=210^{\circ} \mathrm{C}, n_{\mathbf{4 a} / \mathbf{b}}: n_{1}\right.$ $=1: 1$ ) (Table 2). Subsequent DSC measurements do not show any subsequent reactions during the thermal treatment of the materials (Fig. S13†). The large amount of extractable portions can, on the one hand, be attributed to this sterically demanding prepolymer, on the other hand because the polymerization process is a bulk polymerization, i.e. the increasing viscosity during polymerization is a limiting factor for complete conversion. At a temperature of $230{ }^{\circ} \mathrm{C}$ highly foamed partly dark-colored HMs were obtained. TG-MS measurements show that during the polymerization process $\mathrm{CO}_{2}$ and traces of water are liberated (Fig. S17 $\dagger$ ). Urethane and urea increments are, after biuret and allophanate substructures, the most thermally labile compounds in a PU formulation. ${ }^{33-35}$ In order to reduce the thermal load on the samples and thus avoid dissociation of the urethane bonds, only the twin prepolymer $\mathbf{4 a}$ was selected for further experiments involving variation of the monomer ratios at a polymerization temperature of $170{ }^{\circ} \mathrm{C}$. Varying the monomer ratio of $\mathbf{4 a}: \mathbf{1}$ gives no clear trend with regard to the amount of extractable material (Table 3). NMR spectras of the extract showed again prepolymer residues and low molecular weight products such as salicylic alcohol (Fig. S8 and Table S8†).

Solid-state ${ }^{13} \mathrm{C}$ and ${ }^{29} \mathrm{Si}$ NMR spectroscopy proves the formation of the phenolic resin, silica and ODAS (Fig. 3). The different monomer ratios of $\mathbf{4 a}: \mathbf{1}$ are reflected in the NMR spectra and the signal intensities of phenolic resin/ODAS varies correspondingly. An increasing content of the monomer 4a leads to formation of more ODAS structures and thus to more intense D signals, as are shown in the ${ }^{29}$ Si NMR spectra (Fig. 3). A lower monomer 4a ratio gives a strong signal at $-17 \mathrm{ppm}$, which represents $\mathrm{D}(\mathrm{Q})$ species. As expected, HM5a_100 shows only $\mathrm{D}$ and no $\mathrm{Q}$ signals because of the absence of $\mathbf{1}$ as reactant.

The signals of the phenolic carbon and the urethane carbon atom have quite similar chemical shifts within ${ }^{13} \mathrm{C}$ solid state NMR spectra and cannot be distinguished due to broad line widths. The ${ }^{13} \mathrm{C}$ NMR signals in the chemical shift range of 110

Table 3 Summary of experiments performed with different molar ratios of monomers $(n)$ and composition as measured by TGA after extraction. Reaction conditions: $t=2 \mathrm{~h}, T=170{ }^{\circ} \mathrm{C}$

\begin{tabular}{lclll}
\hline Sample & $\begin{array}{c}\text { Monomer ratio } \\
n_{\mathbf{4 a}}: n_{\mathbf{1}}[\mathrm{mol} \%]\end{array}$ & $\begin{array}{l}\text { Extr. cont. } \\
{[\mathrm{wt} \%]}\end{array}$ & $\begin{array}{l}\text { Silica cont. } \\
{[\mathrm{wt} \%] \text { (TGA) }}\end{array}$ & $\begin{array}{l}\text { Silica cont. } \\
{[\mathrm{wt} \%] \text { (calc.) }}\end{array}$ \\
\hline HM5a_05 & $5: 95$ & 21 & 20.9 & 17.6 \\
HM5a_15 & $15: 85$ & 33 & 18.7 & 13.0 \\
HM5a_50 & $50: 50$ & 47 & 10.7 & 8.1 \\
HM5a_85 & $85: 15$ & 25 & 6.1 & 6.5 \\
HM5a_100 & $100: 0$ & 14 & 5.7 & 6.2
\end{tabular}


a)

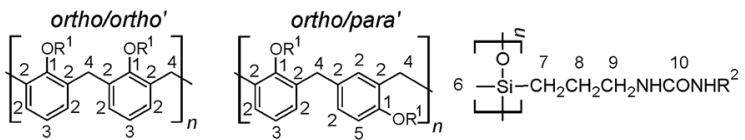

$\mathrm{R}^{1}=\mathrm{H}$, silica, $\mathrm{Si}\left(\mathrm{CH}_{3}\right)\left(\mathrm{C}_{3} \mathrm{H}_{6} \mathrm{NHCONHR}^{2}\right)$

$\mathrm{R}^{2}=$

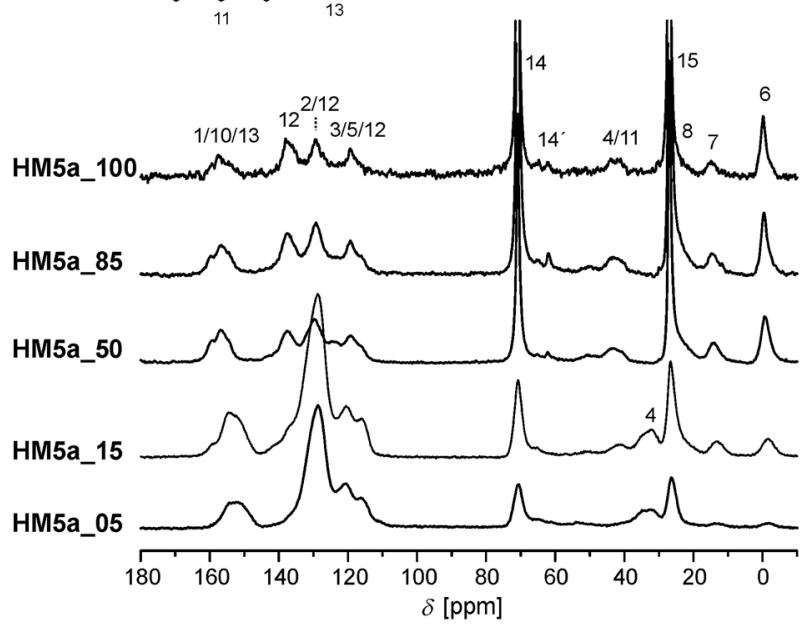

b)
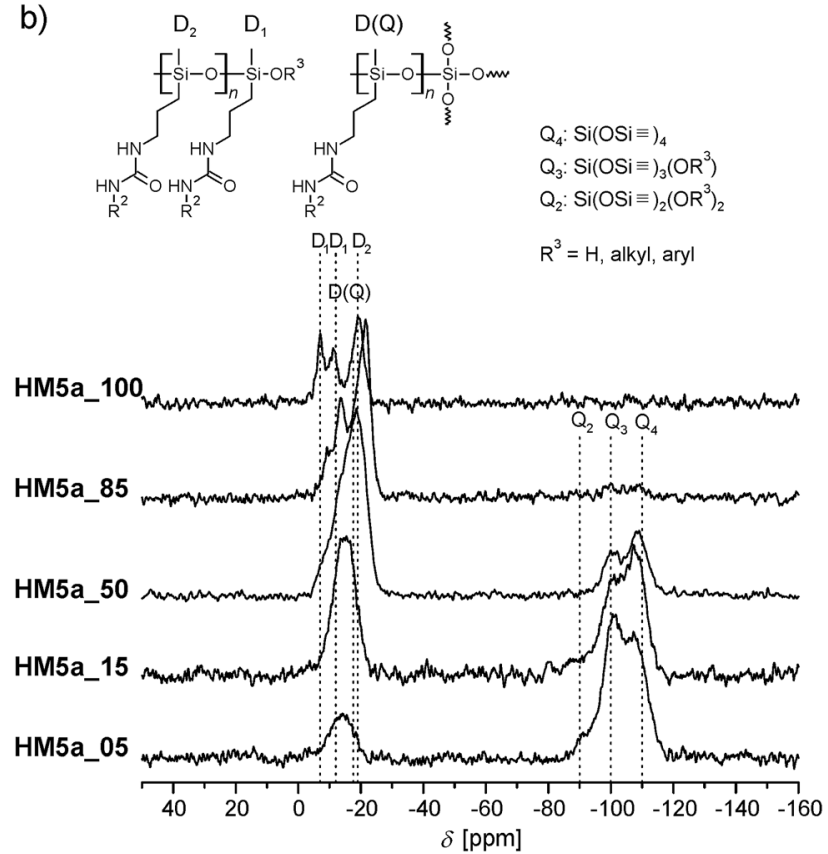

Fig. 3 Solid-state-NMR spectra of selected samples with different molar ratios of the monomers $4 \mathrm{a}$ and 1 . (a) ${ }^{13} \mathrm{C}-\left\{{ }^{1} \mathrm{H}\right\}-\mathrm{CP}-\mathrm{MAS} @ 15 \mathrm{kHz}$ (number of scans: 5a_100 14190; 5a_85 39776; 5a_50 14077; 5a_15 47345; 5a_05 15476) (b) ${ }^{29} \mathrm{Si}-\left\{{ }^{1} \mathrm{H}\right\}-\mathrm{CP}-\mathrm{MAS}(12 \mathrm{kHz}$ (number of scans: 5a_100 14184; 5a_85 45596; 5a_50 62126; 5a_15 15012; 5a_05 14716).

to $140 \mathrm{ppm}$ can be assigned to aromatic carbons. The phenolic resin as well as the used aromatic isocyanate contains such structures. Thus, it cannot be determined with certainty whether phenolic resin is formed in the homo polymerization of prepolymer 4a $\left(n_{\mathbf{4 a}}: n_{\mathbf{1}}=100: 0\right)$. In order to determine whether the twin prepolymer participates in the polymerization reaction under formation of phenolic resin a third twin prepolymer $\mathbf{4 c}$ was synthesized using the aliphatic diisocyanate IPDI (Scheme 5; ESI $\dagger$ ). In the absence of aromatic carbon atoms in the isocyanate component it is possible to determine unequivocally whether phenolic resin is being formed during the homo-polymerization of the twin prepolymer by ${ }^{13} \mathrm{C} \mathrm{NMR}$ spectroscopy. The spectra of $\mathbf{4 c}\left(\mathrm{in} \mathrm{CDCl}_{3}\right)$ and that of its corresponding homo-polymer HM5c_100 are shown in Fig. 4. After the polymerization $\left(170{ }^{\circ} \mathrm{C}, 2 \mathrm{~h}\right)$ and extraction of the $\mathrm{HM}$, characteristic signals in the range 110-133 ppm are seen, demonstrating the formation of phenolic resin even in the absence of co-monomer 1.

As shown in Fig. 3(a), the characteristic ${ }^{13} \mathrm{C}$ signals of the urethane bond and the phenolic resin cannot be identified separately from each other (signals 1,9 and 12 in Fig. 3 ). ${ }^{29} \mathrm{Si}$ $\left\{{ }^{1} \mathrm{H}\right\}$-CP-MAS NMR spectroscopy is used to show the successful polymerization of the dialkyl siloxane increments of the TM end groups (Fig. 3).

In order to test whether the urea increment is present after the polymerization, the HM was investigated by ATR-FT-IR spectroscopy. The materials HM5a-100/85/50/15/5 as well as 4a show, in comparison with prepolymer $3 \mathbf{a}$, an additional band at $1642 \mathrm{~cm}^{-1}$ assigned to the stretching vibration of the $\mathrm{C}=\mathrm{O}_{\text {urea }}$ group. In prepolymer $\mathbf{3 a}$ this band is, as expected, not detectable (Fig. S18†).

All HM were investigated by thermogravimetric analysis (TGA). The samples were heated to $900{ }^{\circ} \mathrm{C}$ under air atmosphere with a heating rate of at $10 \mathrm{~K} \mathrm{~min}^{-1}$ and held for 10 minutes at this temperature in order to guarantee complete removal of the organic content. The quantity of the residue reflects the amount of inorganic material introduced in the HM by variation of the monomers used in each experiment. The thermogravimetric analysis (TGA) of the organic-inorganic HMs shows a slight loss in weight of 4.8 wt\% (HM5a_15) to $9.6 \mathrm{wt} \%$ (HM5a_85) between 30 and $300{ }^{\circ} \mathrm{C}$.

\section{Base catalyzed simultaneous twin polymerization}

Thermally initiated STP of $\mathbf{4 a}$ and $\mathbf{1}$ fabricates to a phenolic resin/ $\mathrm{SiO}_{2} / \mathrm{ODAS}$ nanocomposite in a single step. However, the TP can also be catalyzed by acids or bases. The addition of acid (e.g. lactic acid) to a mixture of $\mathbf{4 a}$ and $\mathbf{1}$ reduces the

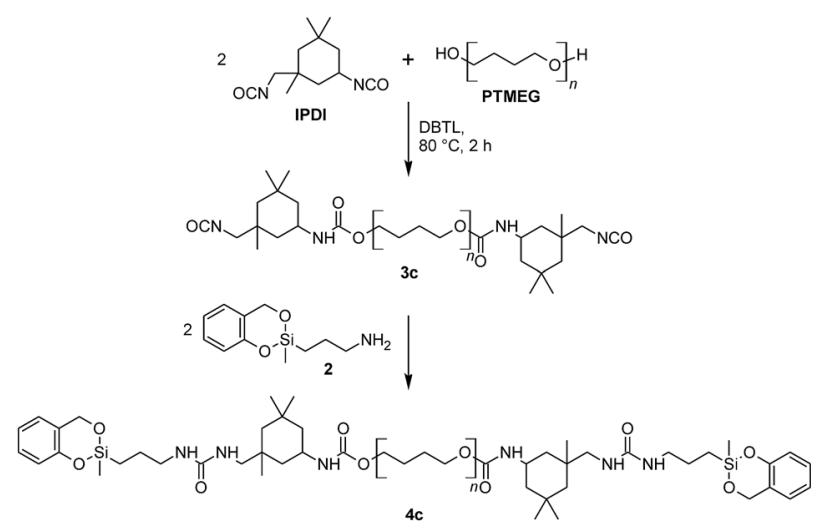

Scheme 5 Preparation of the aliphatic prepolymer $3 c$ with DBTLcatalyst and the end-capping with 2 to obtain 4c. 


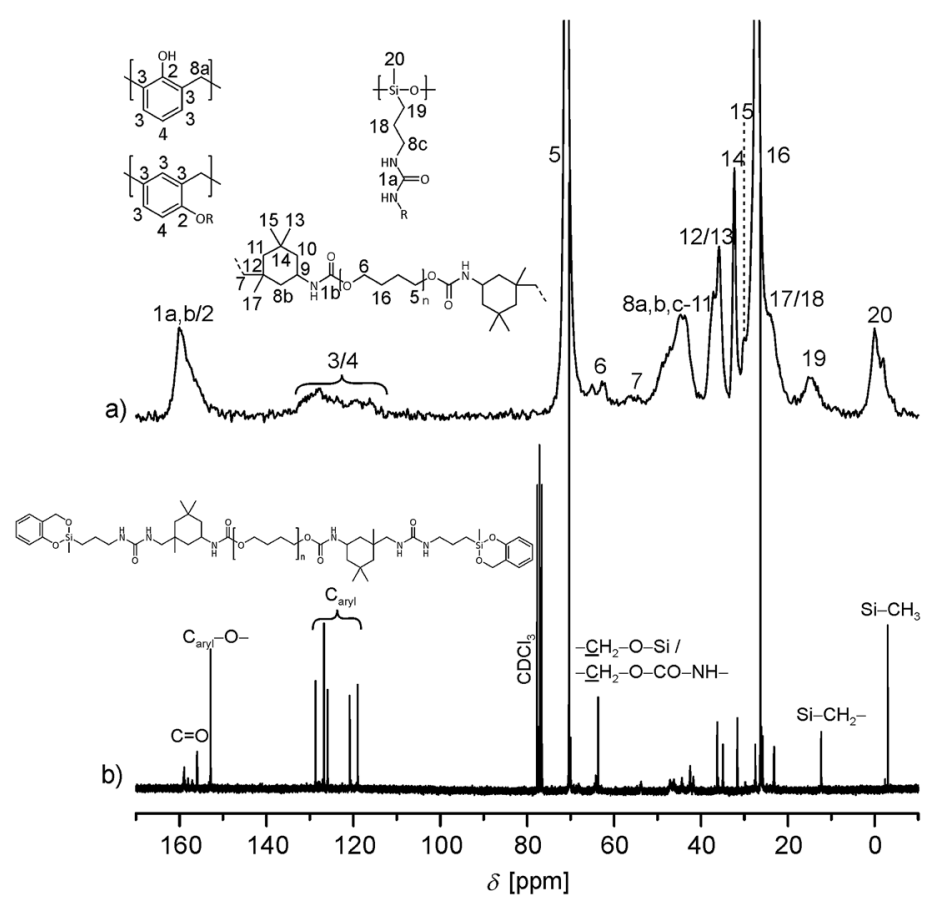

Fig. 4 (a) ${ }^{13} \mathrm{C}-\left\{{ }^{1} \mathrm{H}\right\}$-CP-MAS spectrum of the extracted polymer HM5c_100 prepared by the thermally induced polymerization of $4 \mathrm{c}$. (b) Liquidstate NMR of $4 \mathrm{c}$ (in $\mathrm{CDCl}_{3}$ ).

polymerization temperatures to $80{ }^{\circ} \mathrm{C}$. Unfortunately, the high viscosity results in poor mixing and lead to heterogeneous products. In comparison, the base-catalyzed polymerization of 4a and 1 requires activation temperatures higher than $120^{\circ} \mathrm{C}$ as concluded from DSC measurements (see Fig. 2). Thus, the necessary polymerization temperature lies between those of the thermally induced and the acid-catalyzed polymerizations. 1,4diazabicyclo[2.2.2] octane (DABCO) and 1,8-diazabicyclo[5.4.0] undec-7-ene (DBU) were used as base catalysts. A selection of the experiments performed is shown in Table 4 .

The base-catalyzed STP results in clearly lower extractable portions compared with the thermally induced TP despite the lower reaction temperatures. The soluble extracts show the same composition as for the HM produced by thermal initiation without base as catalyst (Fig. S11†).

High angle annular dark field scanning transmission electron microscopy (HAADF-STEM) investigations were carried out to achieve information on the sizes of the phase domains of the HMs obtained. This technique shows an elemental contrast as well as the contrast attributed to the thickness and the density of the sample. With increasing atomic weight, a higher signal intensity is observed. Thus, the silicon-rich domains of the HM are brighter than the organic polymer. The HAADF-STEM pictures of selected samples with different monomer compositions of $4 \mathrm{a}$ and $\mathbf{1}$ show bright $\mathrm{SiO}_{2}$ clusters with a size of about $2 \mathrm{~nm}$. However, the monomer compositions chosen do not have a significant effect on the domain size (Fig. 5). Si-rich domains are clearly smaller than those found in comparable phenolic resin-silicon dioxide composite materials which were synthesized via sol-gel process. ${ }^{36,37}$

Fig. 6 shows HAADF-STEM pictures of HMs produced from thermally induced and base catalyzed (DABCO) STP of $\mathbf{4 a}$ and $\mathbf{1}$ in equimolar ratio. The silicon distribution within HM5a_base_2 is slightly more homogeneous compared with HM5a_50. STPs of both pre-polymers, $\mathbf{4 a}$ and $\mathbf{4 b}$, respectively, in combination with 1 result in HMs which show a quite similar structure in the high resolution TEM pictures: bright $\mathrm{SiO}_{2}$ clusters with a size of approximately $2 \mathrm{~nm}$ (HM5a_50 polymerized at $170{ }^{\circ} \mathrm{C}$, HM5b_190

Table 4 Summary of the synthesis conditions of the hybrid materials (via base catalyzed STP) and the composition as measured be thermogravimetric analysis (TGA) after extraction. Reaction time $t=2 \mathrm{~h}$. Calculated silica content $=8.1 \mathrm{wt} \%$

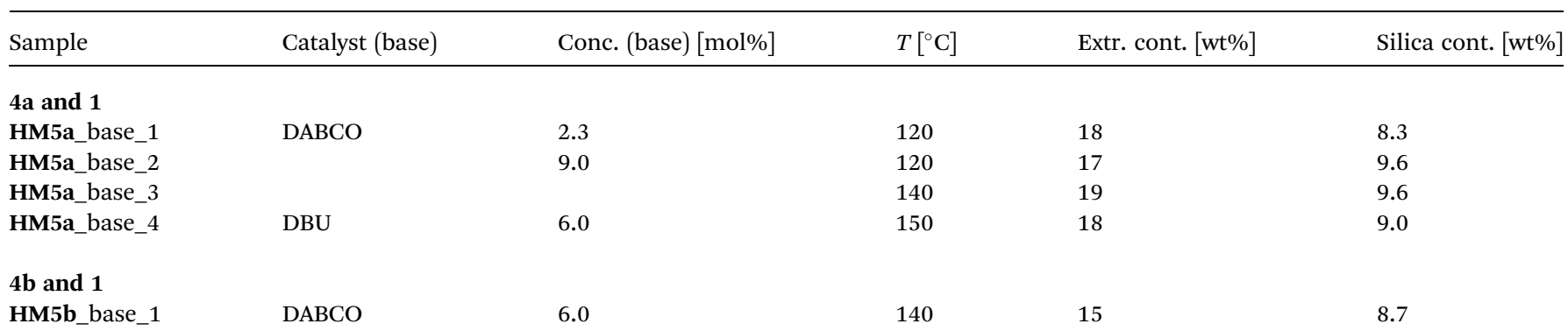



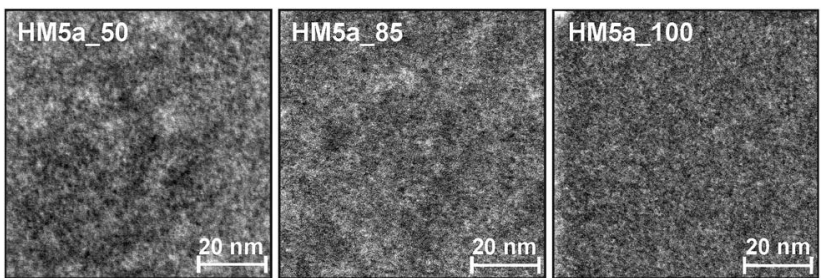

Fig. 5 HAADF-STEM-images of hybrid materials with different monomer ratios of $4 a$ and 1 .
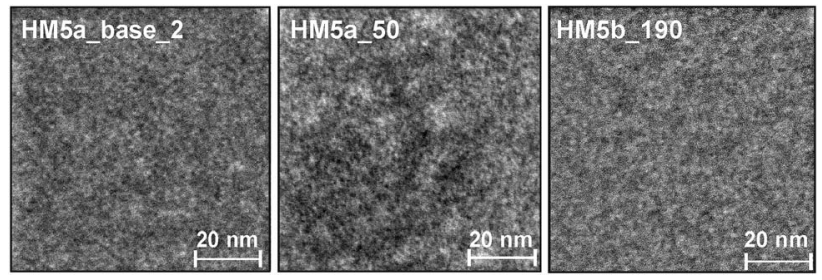

Fig. 6 HAADF-STEM images of the HM prepared by the STP of $4 \mathrm{a}$ and 1 with the use of a base catalyst (HM5a_base_2, DABCO, $9.0 \mathrm{~mol} \% /$ $1 \mathrm{wt} \%, 120^{\circ} \mathrm{C}, 2 \mathrm{~h}$ ), the HM prepared by thermally induced STP of $4 \mathrm{a}$ and 1 (HM5a_50, equimolar, $170{ }^{\circ} \mathrm{C}, 2 \mathrm{~h}$ ) and the $\mathrm{HM}$ prepared by thermally induced STP of $4 \mathrm{~b}$ and 1 (HM5b_190, equimolar, $190^{\circ} \mathrm{C}, 2 \mathrm{~h}$ ).

polymerized at $190^{\circ} \mathrm{C}$, Fig. 6). The monomer ratios chosen have no significant effect on the size of the phase domains.

\section{Conclusions}

Novel twin prepolymers $\mathbf{4 a - c}$ were synthesized and their polymerization ability to produce nanostructured HMs was demonstrated. It was shown that the choice of polymer backbone in the twin prepolymers has an effect on the necessary trigger temperature of the TP. Organic-inorganic HMs are accessible by means of the synergistic combination of twin prepolymers $\mathbf{4 a} / \mathbf{b}$ with $2,2^{\prime}$-spirobi[ $4 H$-1,3,2-benzo-dioxasiline] (1) using STP. The interpenetrating networks resulting from three different polymers result in nanostructured phase domains of approximately $2-4 \mathrm{~nm}$ in size. The different networks are formed on the same time scale. Therefore the phase separation is very small and very similar to the already known hybrid materials from twin polymerization. This represents a completely new procedure for incorporating various types of silicon and phenolic resin into nanoscale urethane formulations. The careful choice of monomer composition and trigger process for polymerization procedure is key for the material properties of the HM produced. A correlation of the molecular structure of the organic-inorganic HM with urethane increments with their macroscopic properties is important for the construction of nanocomposites with specific properties required for industrial applications, e.g. construction of strongly adhering, flexible interlayers in lightweight structures, which is the aim of future work.

\section{Conflicts of interest}

There are no conflicts to declare.

\section{Acknowledgements}

We thank the BASF SE for particular financial support, the providing of chemicals as well as the measurement of the HAADF-STEM-images. This work was also supported by the Deutsche Forschungsgemeindschaft (SCHR 1469/1-1 and the Federal Cluster of Excellence EXC 1075 "Technology Fusion for Multifunctional Lightweight Structures”). Furthermore, we acknowledge Prof. Hietschold and Prof. Tegenkamp for the opportunity of measuring electron microscopy images.

\section{Notes and references}

1 M. Christopher Orilall and U. Wiesner, Chem. Soc. Rev., 2011, 40, 520-535.

2 M. Antonietti, Sci. Bull., 2016, 61, 1662-1664.

3 A.-H. Lu, W.-C. Li, G.-P. Hao, B. Spliethoff, H.-J. Bongard, B. B. Schaack and F. Schüth, Angew. Chem., Int. Ed., 2010, 49, 1615-1618.

4 Y. Yamauchi, N. Suzuki, L. Radhakrishnan and L. Wang, Chem. Rec., 2009, 9, 321-339.

5 M. Antonietti, Nat. Mater., 2003, 2, 9.

6 A. S. Aricò, P. Bruce, B. Scrosati, J.-M. Tarascon and W. van Schalkwijk, Nat. Mater., 2005, 4, 366.

7 A. Thomas, F. Goettmann and M. Antonietti, Chem. Mater., 2008, 20, 738-755.

8 H. S. Thiam, W. R. W. Daud, S. K. Kamarudin, A. B. Mohammad, A. A. H. Kadhum, K. S. Loh and E. H. Majlan, Int. J. Hydrogen Energy, 2011, 36, 3187-3205.

9 Y. Chen, S. Zhou, H. Yang and L. Wu, J. Appl. Polym. Sci., 2005, 95, 1032-1039.

10 S. Karataş, Z. Hoşgör, N. Kayaman-Apohan and A. Güngör, Prog. Org. Coat., 2009, 65, 49-55.

11 S. Karataş, Z. Hoşgör, N.-K. Apohan and A. Güngör, J. Polym. Res., 2010, 17, 247-254.

12 S. Spange, P. Kempe, A. Seifert, A. A. Auer, P. Ecorchard, H. Lang, M. Falke, M. Hietschold, A. Pohlers, W. Hoyer, G. Cox, E. Kockrick and S. Kaskel, Angew. Chem., Int. Ed., 2009, 48, 8254-8258.

13 P. Kempe, T. Löschner, A. A. Auer, A. Seifert, G. Cox and S. Spange, Chem. - Eur. J., 2014, 20, 8040-8053.

14 T. Ebert, A. Seifert and S. Spange, Macromol. Rapid Commun., 2015, 36, 1623-1639.

15 P. Kitschke, A. A. Auer, T. Löschner, A. Seifert, S. Spange, T. Rüffer, H. Lang and M. Mehring, ChemPlusChem, 2014, 79, 1009-1023.

16 S. Spange and S. Grund, Adv. Mater., 2009, 21, 2111-2116.

17 M. Göring, A. Seifert, K. Schreiter, P. Müller and S. Spange, Chem. Commun., 2014, 50, 9753-9756.

18 A. Mehner, A. Pohlers, W. Hoyer, G. Cox and S. Spange, Macromol. Chem. Phys., 2013, 214, 1000-1010.

19 S. Oschatz, A. Lange, S. Csihony, G. Cox, O. Gronwald, A. Seifert and S. Spange, J. Polym. Sci., Part A: Polym. Chem., 2016, 54, 2312-2320.

20 C. Leonhardt, A. Seifert, S. Csihony, H. Sommer and M. Mehring, RSC Adv., 2016, 6, 3091-3098. 
21 L. Kaßner, K. Nagel, R.-E. Grützner, M. Korb, T. Rüffer, H. Lang and S. Spange, Polym. Chem., 2015, 6, 6297-6304.

22 P. Kitschke, M. Walter, T. Rüffer, A. Seifert, F. Speck, T. Seyller, S. Spange, H. Lang, A. A. Auer, M. V. Kovalenko and M. Mehring, J. Mater. Chem. A, 2016, 4, 2705-2719.

23 F. Böttger-Hiller, A. Mehner, S. Anders, L. Kroll, G. Cox, F. Simon and S. Spange, Chem. Commun., 2012, 48, 1056810570.

24 A. Mehner, T. Rüffer, H. Lang, A. Pohlers, W. Hoyer and S. Spange, Adv. Mater., 2008, 20, 4113-4117.

25 T. Löschner, A. Mehner, S. Grund, A. Seifert, A. Pohlers, A. Lange, G. Cox, H.-J. Hähnle and S. Spange, Angew. Chem., 2012, 124, 3312-3315.

26 J. Weißhuhn, T. Mark, M. Martin, P. Müller, A. Seifert and S. Spange, Polym. Chem., 2016, 7, 5060-5068.

27 O. Bayer, Angew. Chem., 1947, 59, 257-272.

28 H.-W. Engels, H.-G. Pirkl, R. Albers, R. W. Albach, J. Krause, A. Hoffmann, H. Casselmann and J. Dormish, Angew. Chem., Int. Ed., 2013, 52, 9422-9441.
29 N. Adam, G. Avar, H. Blankenheim, W. Friederichs, M. Giersig, E. Weigand, M. Halfmann, F.-W. Wittbecker, D.-R. Larimer, U. Maier, S. Meyer-Ahrens, K.-L. Noble and H.-G. Wussow, in Ullmann's Encyclopedia of Industrial Chemistry, Wiley-VCH Verlag GmbH \& Co. KGaA, 2000.

30 U. Meier-Westhues, Polyurethane - Lacke, Kleb- und Dichtstoffe, Vincentz Network GmbH \& Co. KG, Hannover, 2007.

31 H. Zou, S. Wu and J. Shen, Chem. Rev., 2008, 108, 3893-3957. 32 C. Sanchez and F. Ribot, New J. Chem., 1994, 18, 1007-1047. 33 M. Ravey and E. M. Pearce, J. Appl. Polym. Sci., 1997, 63, 4774.

34 F. E. Rogers and T. J. Ohlemiller, J. Macromol. Sci., Chem., 1981, 15, 169-185.

35 S. V. Levchik and E. D. Weil, Polym. Int., 2004, 53, 1585-1610. 36 H. Sardon, L. Irusta, M. J. Fernández-Berridi, M. Lansalot and E. Bourgeat-Lami, Polymer, 2010, 51, 5051-5057.

37 Y. Zhu and D.-X. Sun, J. Appl. Polym. Sci., 2004, 92, 20132016. 